\title{
Costa Caribe de Nicaragua: autonomía, interculturalidad, ética y emancipación social
}

Recepción: 20-10-2016/Aceptación: 28-11-2016

María Dolores Álvarez Arzate ${ }^{1}$ alvarez.antropologa@gmail.com

\section{Resumen}

El propósito de este ensayo es la puesta en perspectiva de la relevancia de la autonomía e interculturalidad en la resolución de problemas prácticos de la sociedad, sustentada en valores éticos humanistas, como instrumento emancipador. Nicaragua es un país que otorga reconocimiento jurídico sobre regiones geográficas compuestas por una diversidad de pueblos originarios: negros, mestizos y otras poblaciones migrantes menos numerosas. El marco jurídico, el sistema educativo, de salud tradicional ancestral y la sociedad en su conjunto, trabajan en la búsqueda del bien común, promoviendo la tolerancia, respeto, equidad, justicia e inclusión, en todos los ámbitos del desarrollo social, económico, político y cultural. El propósito es la construcción de ciudadanias autónomas e interculturales estableciendo y fortaleciendo espacios de diálogo, comunicación e interacción entre personas, comunidades y pueblos de diferentes culturas. La metodología es de tipo cualitativo y asume la Teoría Basada en Datos. En los resultados se abordan dos grandes aspectos, por un lado, el marco juridico general y por otro, las experiencias de autonomía e interculturalidad.

Palabras clave: Interculturalidad, Autonomía, Humanismo, Inclusión.

\section{Abstract}

Purpose of this essay is to put in perspective the autonomy and intercuturality relevance for solving social practical problems, underpinned by bumanistic ethic values, as an emancipate instrument. Nicaragua is a country that ensures legal recognition of geographical regions composed by a diversity of indigenous people; black, mestizo and other les numerous migrant population. Juridical framework, education system, traditional ancestral health system and society work pursuit of the common good, by promoting tolerance, respect, equality, justice and inclusion, in social, economic, political and cultural development. The purpose is construction of autonomics and intercultural citizenship establishing and empowering dialogue spaces, communication and interaction between different cultures individuals, communities and peoples. Methodology is qualitative type and assumes data - base theory. Results address two major aspects, on the one hand, general juridical framework, and in the other hand, experiences of autonomy and interculturality.

Keyword: Interculturality, Autonomy, Inclusion, Humanism

\footnotetext{
1 Doctora en Ciencias Sociales con mención en Gerencia. Docente Titular del Departamento de Antropología. Coordinadora de Posgrado de la facultad de Humanidades y Ciencias Jurídicas, Universidad Nacional Autónoma de Nicaragua, UNAN Managua. Correo electrónico: Alvarez.antropologa@gmail. com, Celular: $505+88529438$
} 


\section{Introducción}

Nicaragua es un país multicultural, multilingüe y pluriétnico que reconoce, desde el punto de vista jurídico, las regiones geográficas que configuran espacios de vida de una diversidad de pueblos: originarios, negros, mestizos y otras poblaciones migrantes, menos numerosas.

Desde el punto de vista administrativo, el país está dividido en 15 departamentos y 2 regiones autónomas ubicadas en la zona Caribe. El Censo de Población y Vivienda del año 2005, mostró que la población de Nicaragua, ascendía a 5,142,098 personas. Entre otros datos importantes se señala que 443,847 personas se auto reconocen como perteneciente a un pueblo indígena o comunidad étnica, lo que representa el 8.6\% de la población nacional. En relación a la población total de las Regiones Autónomas de la Costa Caribe Norte y Costa Caribe Sur, el censó registró un total de 759,383 personas, de ellas se auto identificaron como indígenas y/o afrodescendientes, 253,589 personas, es decir el $33.39 \%$ de la población de las dos regiones autónomas.

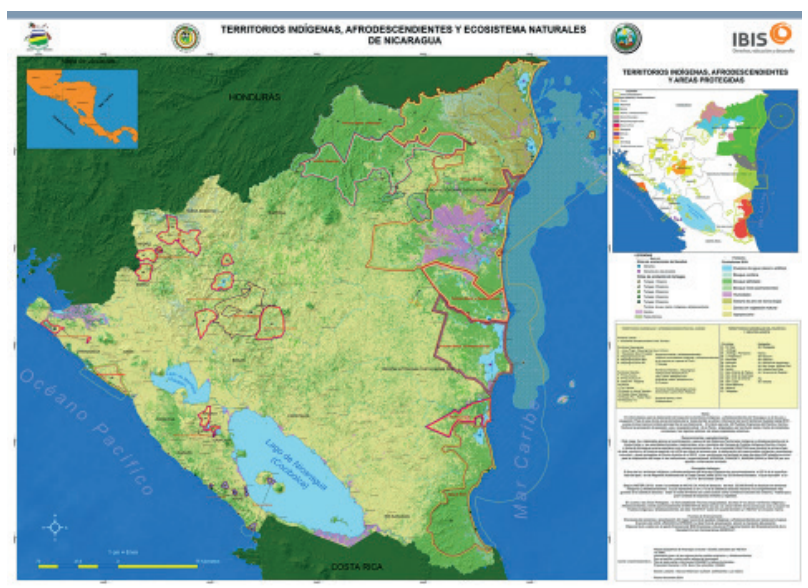

Fuente: Territorios indígenas, afrodescendientes y ecosistemas naturales de Nicaragua. IBIS, Dinamarca (2015).
La Costa Caribe presenta la mayor cantidad de población indígena y afrodescendiente del país. Las regiones autónomas de la costa nicaragüense se distribuye administrativamente compuesta por ocho municipios en la región Autónoma Norte (RACCN), y doce municipios en la Región Autónoma Sur (RACCS). Ambas representan más de la mitad del territorio nacional, albergando al $8.7 \%$ de la población del país.

Las comunidades garífunas de Nicaragua se encuentran localizadas en la cuenca de la Laguna de Perlas, a una distancia de 45 kilómetros al Norte de la ciudad de Bluefields. La extensión territorial que ocupan las comunidades de esta etnia, calculada por el Instituto Nicaragüense de Estudios Territoriales (INETER) es de $532.41 \mathrm{~km}^{2}$. Orinoco, la comunidad principal se localiza a los $12^{\circ} 33^{\prime}$ Latitud Norte y $83^{\circ} 42^{\prime}$ Longitud Oeste (Alvarez Arzate M. \&., 2009, pág. 51).

Las formas de vida cotidiana, tradiciones y costumbres, vinculan a las poblaciones indígenas y afrodescendientes a una cosmovisión propia. La identidad de estas comunidades, están estrechamente vinculada a sus territorios y autoridades comunitarias y territoriales; gastronomía, medio ambiente, derecho consuetudinario, vida confesional, fiestas y ceremonias rituales. Además, el uso de una lengua propia y una historia compartida.

En las comunidades indígenas y afrodescendientes, la organización familiar está fuertemente vinculada a las actividades productivas. La transmisión oral -de generación en generación-, de sus saberes, habilidades, destrezas y actitudes frente a la vida, es una condición natural entre ellos. En el seno de las familias se fomenta el liderazgo e iniciativa. 
La vida cotidiana en las comunidades de los pueblos indígenas tiene dos ámbitos esenciales. El primero, la obtención de recursos y provisión para el consumo familiar, mediante la caza, pesca -en ríos, lagunas y el mar, la recolección, extracción de madera y minerales, y cultivos tradicionales. En el segundo, tiene que ver con el desarrollo de las actividades productivas destinadas al intercambio tradicional (pana-pana para los misquitos y biri-biri para los mayangnas).

Familias indígenas residentes en zonas urbanas, mantienen su vínculo con las comunidades de origen, al incorporar a esta forma citadina, su economía comunitaria. En general, las comunidades afrodescendientes, residen en zonas urbanas, aunque no exclusivamente, teniendo un mayor contacto con la producción artesanal, la prestación de servicios profesionales y el comercio.

El vínculo de estas comunidades étnicas con la economía de enclave de la primera mitad del Siglo XX, marcaron sus concepciones y prácticas laborales. La prestación de servicios domésticos y de campo en las empresas bananeras, mineras y madereras, durante el tiempo que duraron los enclaves, les permitió adquirir experiencias de trabajo en los ciclos productivos de manera particular.

La Costa Caribe de Nicaragua alberga un importante segmento de población que se autodenomina como mestiza costeña. Este grupo Mestizo, es el más numeroso de las regiones autónomas del Caribe, representando el $66.61 \%$ de la población total (INIDE, 2005).

\section{Metodología}

El presente estudio proyecta responder reflexivamente a tres interrogantes: desde el punto de vista ontológico, ¿Cuál es la forma y naturaleza de la realidad?; orientada a la relevancia de la autonomía y la interculturalidad en la resolución de problemas prácticos de la sociedad con base en valores éticos humanistas como instrumento emancipador. Desde el epistemológico, ¿Cuál es la naturaleza de la relación entre el conocedor o el posible conocedor y qué es aquello que puede ser conocido?, las visiones de las/los protagonistas acerca de las categorías autonomía e interculturalidad; y el último metodológico ¿Cómo el investigador puede descubrir aquello que él cree puede ser conocido? en otras palabras, la relación práctica entre la autonomía e interculturalidad para generar las estrategias orientadas a la resolución de conflictos (Guba \& Lincoln, 1994),

La investigación es de tipo cualitativo y tuvo como referencia principal los enfoques metodológicos de las teorías interpretativas iniciadas por Oevermann (Oevermann, 1983), continuadas posteriormente por Heidegger (Heidegger, 1927/1986) y Gadamer, acerca de la hermenéutica objetiva (Gadamer, 1960/1972/1975). Se toma en cuenta la postura de Weber sobre la teoría de la acción social y sociología comprensiva (Weber, 1964), Geertz y la interpretación de las culturas (Geertz C. , 1988).

El paradigma científico que siguió la investigación corresponde a la Teoría Crítica. Desde el punto de vista y metodológico sigue el enfoque de la Teoría Basada en Datos de Glaser y Strauss (Glaser, 1967), autores que consideran que la creación de teoría, se logra por medio de la recolección de 
datos, análisis y síntesis que permita explicar los procesos sociales estudiados.

Las metodología de la investigación se desarrolló a partir de la importancia de un proceder flexible, franqueza en la determinación de los conceptos previos, baja incidencia de las/los investigadores en el contexto y con los sujetos investigados, análisis inductivo basado en datos empíricos, construcción de categorías e hipótesis de trabajo y validación de los resultados con expertas/expertos. Las técnicas utilizadas fueron la observación, entrevista y análisis documental.

\section{Resultados y discusión}

\section{Marco jurídico general.}

Nicaragua es un país que reconoce la multiculturalidad de la población, hecho que se verifica a nivel internacional y nacional a partir de la legislación nacional y la suscripción de instrumentos internacionales que se describen en los párrafos subsiguientes.

En Nicaragua, el Estado ha suscrito importantes documentos atingentes a los Pueblos Indígenas, entre ellos: 1) Convención Internacional sobre la Eliminación de Todas las Formas de Discriminación Racial (1965), ratificado por Nicaragua en 1979; 2) Convenio 169 de la OIT sobre Pueblos Indígenas y Tribales en Países Independientes (1989), ratificado por Nicaragua en 2010; 3) Declaración de las Naciones Unidas sobre los Pueblos Indígenas 2007, ratificado por Nicaragua en 2007; 4) Convención sobre la Eliminación de todas las formas de Discriminación contra La Mujer (1979) firmada por Nicaragua en 1980.

Nicaragua, en materia de derechos de los Pueblos
Indígenas reconoce y suscribe instrumentos internacionales tales como, la Convención Internacional sobre la Eliminación de Todas las Formas de Discriminación Racial (ratificada por el Consejo de Estado el 18 de Diciembre de 1979), de la cual Nicaragua es parte, define: "Discriminación Racial:" toda distinción, exclusión, restricción o preferencia basada en motivos de raza, color, linaje u origen nacional o étnico, que tenga por objeto o por resultado anular o menoscabar el reconocimiento, goce o ejercicio, en condiciones de igualdad, de los derechos humanos y libertades fundamentales en las esferas política, económica, social, cultural o en cualquier otra esfera de la vida pública". En el artículo 2, inciso C se establece que: cada Estado parte tomará medidas efectivas para revisar las políticas gubernamentales nacionales y locales y para enmendar, derogar o anular las leyes y las disposiciones reglamentarias que tengan como consecuencia crear la discriminación racial o perpetuarla donde exista.

El Convenio 169 de la OIT sobre Pueblos Indígenas y Tribales en Países Independientes fue aprobado en 1989 por las Naciones Unidas con el voto del Gobierno de Nicaragua, ratificado por Nicaragua el 6 de mayo del 2010. El Convenio establece que los gobiernos de los Estados que lo ratifiquen deben consultar sobre toda política o programa gubernamental que involucre a los pueblos y comunidades indígenas. En su artículo 7 inciso 1, el convenio plantea la potestad de los indígenas como colectividad territorial para gobernar (decidir sus propias prioridades) su propio desarrollo, lo que tiene fuertes implicaciones para el andamiaje jurídico administrativo del país ratificante.

La Declaración de Naciones Unidas sobre los De- 
rechos de los Pueblos Indígenas de 2007, ratificada por Nicaragua en 2007, establece que (artículo 26.-1) "se respetará debidamente las costumbres, las tradiciones y los sistemas de tenencia de la tierra de los pueblos indígenas de que se trate".

La Convención sobre la Eliminación de todas las formas de Discriminación contra La Mujer (1979), suscrita por Nicaragua en 1980, reafirma: "la promoción del respeto a los derechos humanos y a las libertades fundamentales, sin distinción de ninguna especie, incluida la motivada por el sexo lo cual se consigna como principio en el Estatuto Fundamental y en el Estatuto sobre Derechos y Garantías que rigen en la República”.

Las resoluciones de la Corte Interamericana de Derechos Humanos han sido dictadas a favor de los derechos de las poblaciones indígenas. El 31 de agosto de 2001, la Corte Interamericana de Derechos Humanos (CIDH) dictó sentencia sobre el caso de la Comunidad Mayangna (Sumo) Awas Tingni vs. Nicaragua. Fondo, reparaciones y costas, relativas a la demarcación de sus territorios con base a sus derechos ancestrales. El 23 de junio de 2005, la CIDH dictó sentencia en el caso de YATAMA vs. Nicaragua. Fondos, reparaciones y costas, relativas a los derechos políticos indígenas con base en el respeto a las formas consuetudinarias de elegir a sus representantes.

Nicaragua reconoce la multiculturalidad del país en diversos instrumentos jurídicos de ámbito nacional, tales como: la Constitución Política de la República de Nicaragua, 1987 y sus Reformas de 1995 y 2000; el Estatuto de Autonomía de las Regiones de la Costa Atlántica de Nicaragua, 1987; la Ley General de Educación, 2006; la Ley de Uso Oficial de Lenguas de las Comunidades de la Cos- ta Atlántica Nicaragüense, 1996; el Código de la Niñez y Adolescencia, 1998; la Ley de Municipios, sus Reformas e Incorporaciones, 2012; la Ley de Régimen de Propiedad Comunal de los Pueblos Indígenas y Comunidades Étnicas de las Regiones Autónomas de la Costa Atlántica de Nicaragua y de los ríos Bocay, Coco, Indio y Maíz, 2003; la Ley de Reforma y Adición a la Ley No. 290, Ley de Organización, Competencia y Procedimientos del Poder Ejecutivo, 2012. Creación del Ministerio de Economía Familiar, Comunitaria, Cooperativa y Asociativa (MEFCCA); la Ley 759 o Ley de Medicina Tradicional Ancestral La Ley 759, 2011.

La Constitución de la República de Nicaragua en su Preámbulo, evoca "La lucha de nuestros antepasados indígenas", y diversos de sus artículos reconocen la existencia de los pueblos indígenas, su propiedad comunal y manda a la Ley de Municipios a establecer las competencias municipales con los pueblos indígenas. En, Constitución Política de la República de Nicaragua de 1987 y sus reformas, Ley de Reforma Parcial de la Constitución Política de la República de Nicaragua - Ley No. 192 del 1 de febrero de 1995.

La Constitución de la República de Nicaragua, sin distinciones, reconoce la existencia de los pueblos indígenas, y se refiere a ellos de la siguiente manera: Artículo 5: el Estado reconoce la existencia de los pueblos indígenas, que gozan de los derechos, deberes y garantías consignadas en la Constitución y en especial los de mantener y desarrollar su identidad y cultura y tener sus propias formas de organización social y administrar sus asuntos locales; así como mantener las formas comunales de propiedad de sus tierras y el goce, uso y disfrute de las mismas, todo de conformidad con la ley, y reconoce además el proceso autonómico de 
las regiones del Caribe. El capítulo VI, artículos 89, 90 y 91, establece los derechos de las comunidades indígenas, y particularmente el artículo 91 establece que El Estado tiene la obligación de dictar leyes destinadas a promover acciones que aseguren que ningún nicaragüense sea objeto de discriminación por razón de su lengua, cultura y origen.

La Constitución define en el Articulo No. 8, que: "para las comunidades de la Costa Atlántica se establece el régimen de autonomía en la presente Constitución" y define que el pueblo de Nicaragua es de naturaleza multiétnica y parte integrante de la nación centroamericana.

Nicaragua ha aprobado la Ley No. 28 o Estatuto de Autonomía de las Regiones de la Costa Atlántica de Nicaragua, publicados en La Gaceta, Diario Oficial, No. 238 del 30 de octubre de 1987. El Estatuto de la Autonomía fue aprobado el 2 de septiembre de 1987 (Ley No. 28) y fue reglamentado por la Asamblea Nacional el 9 de julio del 2003.

El estatuto de Autonomía (Ley 28) define, en su Artículo 3, como régimen de autonomía: el sistema o forma de gobierno, jurídico, político, administrativo, económico y financieramente descentralizado dentro de la unidad del Estado nicaragüense, establece las atribuciones propias de las Regiones Autónomas de la Costa Atlántica de Nicaragua, de sus órganos de administración, los derechos y deberes que corresponden a sus habitantes para el ejercicio efectivo de los derechos históricos de los pueblos indígenas y comunidades étnicas de la Costa Atlántica de Nicaragua.

El Estatuto de Autonomía (Ley 28), explicita que una de las atribuciones de las regiones autónomas, es recibir del gobierno central recursos y medios necesarios para administrar los programas de salud, educación, cultura, transporte, servicios básicos, deportes e infraestructura en coordinación con las instancias o ministerios correspondientes tomando en cuenta las condiciones particulares de la Costa Atlántica, los que deben ser incluidas en el Presupuesto General de la República.

La Ley de Reforma a la Ley $\mathrm{N}^{\circ} 28$, Estatuto de la Autonomía de las Regiones de la Costa Atlántica de Nicaragua, Ley No. 926, Aprobada el 15 de Marzo del 2016, publicada en La Gaceta No. 59 del 31 de marzo del 2016. La presente ley tiene por objeto adecuar la Ley $\mathrm{N}^{\circ} 28$, Estatuto de la Autonomía de las Regiones de la Costa Atlántica de Nicaragua", publicada en La Gaceta, Diario Oficial No. 238 del 30 de octubre de 1987, conforme la Constitución Política de la República de Nicaragua, cuyo texto íntegro con sus reformas incorporadas fue publicado en La Gaceta, Diario Oficial No. 32 del 18 de febrero de 2014. La Ley 926 dice literalmente: Refórmese el título de la Ley No. 28, Estatuto de Autonomía de las Regiones de la Costa Atlántica de Nicaragua, sustituyendo "Costa Atlántica" por "Costa Caribe", en consecuencia se leerá así: "Ley No. 28, "Estatuto de Autonomía de las Regiones de la Costa Caribe de Nicaragua".

La Ley General de Educación (Ley No. 582), enfatiza en el respeto a la equidad, acceso y permanencia en la educación, esta ley establece que toda persona tiene derecho a la educación en condiciones de igualdad con la misma calidad, en la que se logren conjugar las necesidades sociales y locales (Art. 7), y garantiza que, el ingreso a la educación pública es libre, gratuito e igual para todos los y las nicaragüenses (Art.8). 
La Ley 582 (Art.3 h) define la existencia del Subsistema de Educación Autonómica Regional de la Costa Caribe Nicaragüense (SEAR), reconoce el derecho de la RAAS y RAAN de contar con un modelo educativo propio, orientado a la formación integral de las mujeres y hombres de los pueblos indígenas, afrodescendientes y comunidades étnicas, basado en los principios de autonomía, interculturalidad, solidaridad, pertinencia, calidad, equidad, así como valores morales y cívicos de la cultura regional y nacional; comprometidos y comprometidas con el desarrollo sostenible, la equidad de género y los derechos de niños, niñas, adolescentes y jóvenes.

El SEAR tiene como uno de sus ejes fundamentales, la interculturalidad, promueve una sólida preparación científica, técnica y humanista fortaleciendo su identidad étnica, cultural y lingüísti84 ca que contribuyan al proyecto de unidad en la diversidad. La Autonomía Educativa Regional comprende la Capacidad Jurídica de las Regiones Autónomas de dirigir, organizar y regular la educación en todos sus niveles en sus respectivos ámbitos territoriales, de conformidad a sus usos, tradiciones, sistemas de valores y culturas, en coordinación con las entidades nacionales a cargo de la educación. (Ley 582, Art. 38-42).

La Ley de Uso Oficial de Lenguas de las Comunidades de la Costa Atlántica Nicaragüense (Ley No. 162), en su Artículo 2 establece que: las comunidades de la Costa Atlántica tienen derecho a la preservación de sus lenguas. El Estado establecerá Programas especiales para el ejercicio de este derecho. Esta ley reconoce que las lenguas de las comunidades de la Costa Atlántica de Nicaragua serán de uso oficial y por lo tanto merecen la protección del Estado para su preservación y para que ningún nicaragüense sea objeto de discriminación por razón de su lengua. Las lenguas miskitu, creole, sumu, garífuna y rama son lenguas de uso oficial en las Regiones Autónomas de la Costa Atlántica, así como en los departamentos de Jinotega y Nueva Segovia, para el caso del miskitu y sumu.

El Código de la Niñez y Adolescencia (Ley 287), garantiza que todas las niñas, niños y adolescentes tienen derecho a disfrutar del más alto nivel posible de salud física y mental, educación, tiempo libre, medioambiente sano, vivienda, cultura, recreación, seguridad social y a los servicios para el tratamiento de las enfermedades y rehabilitación de la salud. (Art. 33).

La misma Ley, en el Arto. 8 dice que, a las niñas, niños y adolescentes que pertenezcan a Comunidades Indígenas, grupos sociales étnicos, religiosos o lingüísticos o de origen indígena, se les reconoce el derecho de vivir y desarrollarse bajo las formas de organización social que corresponden a sus tradiciones históricas y culturales.

El Estado garantizará a las niñas, niños y adolescentes que pertenezcan a tales comunidades indígenas o grupos sociales, a tener los derechos que le corresponden en común con los demás miembros de su grupo, a tener su propia vida cultural, educativa, a profesar y practicar su propia religión, costumbres, a emplear su propio idioma y gozar de los derechos y garantías consignados en el presente Código y demás leyes.

Reformas e Incorporaciones a la Ley No. 40, "Ley de Municipios “; Publicada en la Gaceta, Diario Oficial, No. 155 de 17 de agosto de 1988, las que incorporadas a la ley se leerán así: Leyes No. 40 y 261 del 28 de junio de 1988, publicada en La 
Gaceta No. 162 de 26 de agosto de 1997. Las reformas incluyen aspectos específicos relacionados a la forma de desarrollar la vida municipal en las regiones autónomas, que literalmente dice: Título VI. De los municipios y las comunidades indígenas. Capítulo I. De los municipios en las regiones autónomas. Artículo 62: Los Municipios ubicados en las Regiones Autónomas Atlántico Norte y Atlántico Sur se regirán por el Estatuto de Autonomía de las Regiones de la Costa Atlántica de Nicaragua y la presente Ley. En virtud de la autonomía regional y municipal, y en aras de una eficiente y racional prestación de servicios a la población, se deberán establecer entre los gobiernos municipales y regionales correspondientes relaciones de coordinación, cooperación, mutua ayuda y respeto a cada una de las esferas de competencia.

La misma Ley de Municipios refiere que, en su Artículo 63: los Concejos Municipales de los Municipios ubicados en las Regiones Autónomas de la Costa Atlántica, al aprobar la creación de las instancias administrativas u órganos complementarios de administración en sus ámbitos territoriales, reconocerán y respetarán el derecho de los pueblos indígenas y comunidades étnicas, a organizarse socialmente en las formas que correspondan a sus tradiciones históricas y culturales.

La Ley 445, Ley de Régimen de Propiedad Comunal de los Pueblos Indígenas y Comunidades Étnicas de las Regiones Autónomas de la Costa Atlántica de Nicaragua, publicada en La Gaceta el 23 de enero de 2003, (Arto. 23) señala que El Estado reconoce la personalidad jurídica de las Comunidades Indígenas y étnicas sin más trámite, asimismo reconoce el derecho constitucional de éstas para darse sus propias formas de gobierno interno. Visto de esta forma, y de acuerdo a lo establecido en la Ley de Municipios (Ley No. 40), además del Gobierno Central, Nicaragua tiene tres sub niveles de gobierno: regional, municipal y comunal. Este primer elemento indica que cualquier acción que desarrolle el Sistema de Bienestar Social debe comunicarse y consensuarse con los Gobiernos Territoriales, municipales y comunales. Aprobada el 13 de Diciembre del 2002. Publicado en La Gaceta No. 16 del 23 de Enero del 2003. En el Capítulo VIII, Procedimiento para la legalización de las tierras, dice literalmente: Artículo 40. El trabajo de demarcación y reconocimiento legal de la propiedad territorial de las comunidades indígenas y étnicas, cuya iniciación impulso y ejecución se realizaran en los términos, por las entidades y personas que se señala en normas posteriores de esta misma Ley, se cumplirán en todo su desarrollo con pleno respeto y sujeción a los siguientes principios y criterios generales: a) La plena participación directa de los pueblos indígenas y comunidades étnicas con voz y voto, a través de sus autoridades tradicionales. b) La disposición y voluntad permanente de concentración y de armonía entre las diferentes instituciones y personas involucradas en el desarrollo de los trámites del proceso. c) La determinación de la superficie y limite de los espacios territoriales a reconocer, tomando en cuenta la posesión histórica reconocida por la comunidad o comunidades solicitantes; d) La voluntad de contribuir de manera pacífica y razonable a la búsqueda de solución a los eventuales conflictos que puedan suscitarse entre comunidades o agrupaciones de comunidades colindantes o vecinas en sus asentamientos.

La Ley 445, subsana leyes precedentes que se propiciaron entre 1877 y 1908 leyes de venta forza- 
da de sus territorios. En 1918 estas leyes fueron derogadas pero las comunidades indígenas ya habían perdido muchas de sus tierras. En el año 2000, la Ley 278, Ley de la Propiedad Reformada Urbana y Agraria, estableció que "Las personas que han recibido títulos de Reforma Agraria en territorios de las Comunidades Indígenas, deben pagar el Canon de Arriendo a la Comunidad", reconociendo así el derecho de las comunidades como colectividad territorial.

Las leyes reconocen el valor e importancia de las formas de organización tales como el Consejo de Ancianos, la Junta Directiva de la Comunidad y la Asamblea Comunal: a) El Consejo de Ancianos es nombrado entre los hombres más viejos del grupo, y sus principales decisiones tienen que ver con la conducción de los destinos de pueblos indígenas y resoluciones ante situaciones de importan86 cia en la vida de la comunidad. Otra función es la de ser los depositarios de la memoria histórica del pueblo indígena; b) La Junta Directiva que sirve como representante del Gobierno Comunal. Esta junta sí es elegida mediante un proceso electoral de la comunidad. Estas personas son electas por un período de dos años y para ello se constituye un grupo de siete personas; c) Asamblea Comunal, constituida por toda la población de la comunidad indígena.

La Ley 759 o Ley de Medicina Tradicional Ancestral, aprobada el 21 de junio de 2011. Publicada en La Gaceta No. 123 del 04 de Julio del 2011, tiene como objeto reconocer el derecho, respetar, proteger y promover las prácticas y expresiones de la medicina tradicional ancestral de los pueblos indígenas y afro-descendientes en todas sus especialidades y el ejercicio individual y colectivo de los mismos, en función de la salud propia e intercultural y establecer las garantías adecuadas que corresponden al Estado para su efectiva aplicación y desarrollo.

Ley de Reforma a la Ley No. 331, Ley Electoral, Ley No. 790, Aprobada el 15 de Mayo de 2012. Publicado en La Gaceta No. 95 del 23 de Mayo de 2012. En su Arto. 82 mandata a los partidos políticos o alianzas de partidos que participan en las elecciones municipales, de diputados y diputadas de la Asamblea Nacional y el Parlamento Centroamericano, quienes deberán presentar en sus listas de candidatos un cincuenta por ciento de hombres y un cincuenta por ciento de mujeres ordenados de forma equitativa y presentada de manera alterna.

Ley 804, Ley de Reforma y Adición a la Ley No. 290, Ley de Organización, Competencia y Procedimientos del Poder Ejecutivo. Arto. 29 que se refiere a la creación del Ministerio de Economía Familiar, Comunitaria, Cooperativa y Asociativa. Aprobado en la Asamblea Nacional en julio de 2012. En su Arto. 29 refiere Modelo productivo indígena y afro descendientes: Apoyar la implementación del Modelo Productivo Indígena y Afro descendiente como una forma sostenible y eficiente de modelo productivo complementando métodos ancestrales con los conocimientos actuales de producción y la consolidación de unidades productivas indígenas y afrodescendientes, que generen intercambio y comercialización de productos, asegurando la autosuficiencia alimentaria, la generación de ingresos y de empleos para las familias indígenas y afro-descendientes y que sustente el buen vivir de sus pueblos y comunidad". 
Los Consejos Regionales en la RACCN y la RACCS han aprobado una serie de resoluciones que tienen fuerza de Ley en su respectiva jurisdicción, entre las que se destacan las políticas de género de las regiones. Resoluciones que profundizan muchos de los preceptos emanados del marco jurídico nacional.

\section{Autonomía e Interculturalidad.}

La Autonomía es una categoría esencial para el ejercicio de la Interculturalidad como parte del proceso permanente de construcción, establecimiento y fortalecimiento de espacios de diálogo, comunicación e interacción entre personas, comunidades y pueblos de diferentes culturas. En Nicaragua, como país multiétnico y multicultural, la identidad cultural se vive en dimensiones mixtas, no se es totalmente perteneciente a un fenotipo como tampoco lo es a una identidad cultural.

Ahora bien, las personas cuya constitución familiar contiene un matrimonio mixto, ya sea de abuelos o de padres, un elemento o varios elementos culturales de uno se pasan al próximo en la socialización primaria que ocurre en la familia. Esta identidad racial-cultural sufre constantes conflictos en los cuales las personas deben decidir $\mathrm{y}$ auto identificarse. Hecho que resulta complejo y lleva al sujeto a asumir propios y desprenderse de ajenos. Acto que no siempre alcanza un nivel de aceptación colectiva.

La oralidad transmitida en leyendas necesita del acompañamiento de las prácticas de sus portadores, y se presentan situaciones en la que esta transmisión no ocurre y se pone en riesgo la perdurabilidad de la identidad cultural.
Los negros relacionados con las compañías de enclave, en donde trabajaron sus padres y sus abuelos, tenían acceso a observar y aprender de las formas de vida de los llamados "jefes" y del "staff". Los cual se vivió en la niñez como un gran suceso sin tener conciencia de la trascendencia de lo vivido. A pesar de la relación asimétrica entre los creoles y los norteamericanos, lo aprendido se llevó a las vida presente y marca un estatus superior y una cultura distinta al resto de la población costeña.

La raza negra y la identidad cultural creole facilitaba el acceso pero la abundancia estaba acompañada de explotación. Cuando las compañías se retiran del país en la década de 1980, los trabajadores directos y los indirectos perciben un gran vacío y empiezan a vivir en carencia y pobreza. Algunas familias creoles centran su esperanza en la formación técnica o profesional de sus hijos, lo que les garantizaba conservar su estatus en la sociedad.

Sin embargo la búsqueda de la educación como estrategia de estatus para alcanzar un mejor nivel de vida, llevó a los negros costeños a realizar sus estudios de secundaria en Bluefields ya que allí se encontraban las mejores instituciones educativas de la región. Este hecho, por sencillo que parezca da como resultado que en el imaginario colectivo se asume como doxa que la Costa Caribe es Bluefields y su raza predominante es negra.

Otro factor importante en la configuración de la identidad cultura costeña es la pertenencia a una filiación confesional. Los negros creole son moravos, los mískitos en su mayoría son moravos, en tanto los negros garífunas son mayoritariamente católicos. Un hecho que marca la preponderancia morava en la Costa Caribe es la enseñanza de la 
Biblia en inglés que cubre la población creole y su rápida traducción de la Biblia al mískitu como "Dawan Bîla Aiska" (Sociedades Bíblicas, 1974).

La religión como eje de la formación ética y religiosa, la formación en normas y valores tiene gran influencia en la actualidad y sus raíces se encuentran en la vida diaria de los pobladores.

Las clases sociales y pureza étnica fueron una constante en la formación de identidad cultural en la Costa Caribe, Las Minas, irradiando a los territorios vinculados a las compañías de madera, banano y minería, lo cual se expresó con bastante claridad en la configuración de la pirámide social, en la cúspide los norteamericanos, luego creoles y finalmente, en la base, los pueblos indígenas, tales como los miskitu y sumu mayangna.

En la cultura garífuna, la vida económica es resul88 tado de la conjugación de varios factores, entre ellos el clima, las estaciones del año, los períodos de apareamiento y reproducción de las especies acuáticas y terrestres, la vocación de los suelos, el manejo del agua y la relación con las costas, los humedales y el bosque tropical (Alvarez Arzate M. \&., 2009).

La relación de la población garífuna con el territorio tiene ahora más importancia debido al avance de la frontera agrícola y la falta de un reconocimiento institucional de sus territorios, lo cual afecta la vida jurídica y productiva de la población (Alvarez Arzate M. \&., 2009).

En la cultura garífuna, el desarrollo humano indica que existe una gran riqueza de instrumentos de trabajo y formas de producción, cada una relacionada al tipo de producto que se desea obtener, ya sea de la pesca, la cacería, la agricultura o el cui- do de animales. En la pesca se identifica: cayuco, lancha, atarraya, anzuelo, redes, machete, remos, trasmallo, canalete. En la agricultura se identifica: macana, azadón, machete y hacha. Algunas prácticas cotidianas se han visto modificadas con la llegada de la energía eléctrica, para unos es un avance, para otros un hecho que les invade y contamina (Alvarez Arzate M. \&., 2009, pág. 58).

En los distintos pueblos originarios y afrodescendientes, el contacto con la sociedad nacional y el aprendizaje del español como lengua para ingresar a la educación superior, permitió el manejo de la lengua materna (L1) y una segunda lengua (L2). Esta situación marcó la distancia entre personas y poblaciones monolingües y bilingües en la misma Costa Caribe.

En el presente, la implementación del Subsistema de Educación Autonómica Regional de la Costa Caribe Nicaragüense ha contribuido a la revitalización de las lenguas propias, la cual fue afectada por la castellanización de la década de 1960. Esta situación incluye el aprendizaje de otros juegos de otras canciones de otras culturas y se pasa a un segundo plano la identidad originaria.

La identidad cultural de las poblaciones mískitas se conserva a través del sistema social conocido como Taya Nani que constituye una red familiar y social extremadamente sólida y entrecruzada de alianzas, que aúna perdura y es respetada como una institución sociale más fuerte de la población mískita.

La lectura apropiada de los mensajes de la naturaleza se ha perdido en la tradición oral como parte de la identidad cultural. Sin embargo, son frecuentes los ejemplos en los cuales la voz de la memoria colectiva hizo uso de la identidad cultu- 
ral y apoyó positivamente a las poblaciones, sobre todo cuando se trata de fenómenos naturales.

La identidad cultural de la población mískita descansa en una serie de instituciones culturales que son respetadas, y a su vez son fuente de negociación para el entendimiento y respeto entre los practicantes.

Un estudio realizado por Salvador García (García, 2013, págs. 13-15), contribuye a comprender los principios y valores de las culturas y toma como base, la experiencia del pueblo miskitu. En la cultura miskitu se usa la palabra laka (ley) para institucionalizar las normas sociales, orientadas a lograr comportamientos concretos. Así, presentamos algunos de los más importantes principios ideales del sistema social miskitu:

Laman Laka: laman se asocia a la calma de las aguas, cuando una laguna o el río están mansos; Pana Laka: es la solidaridad social, el apoyarse unos a otros en actividades productivas y los ciclos vitales de ayuda intrafamiliar; Asla Laka: es el sentimiento de unidad entre los individuos, entre ellos y las autoridades, y entre las autoridades en relación a toda la comunidad en función de objetivos comunes; Kupia Kumi Laka: es la búsqueda de consenso para desarrollar actividades públicas de la comunidad; Latuan Laka: es la capacidad de sentir amor por los otros y de conmoverse por el dolor de los otros; Klin Laka: es el mandato para la implementación de un conjunto de prácticas higiénicas de limpieza en función de la salud individual, pública, la autoestima y la imagen de orden y limpieza que proyectan hacia afuera como familia y comunidad;
Pri Laka; es la libertad que tienen todas las personas para desplazarse por el territorio sin imposiciones, utilizar los recursos que le corresponden a cada uno por derecho consuetudinario y ejercer plenamente su propio pensamiento político y sus creencias religiosas.

En consecuencia, se afirma que, la sociedad de la Costa Caribe Norte, la identidad cultural reposa en las siguientes dimensiones: 1) los mitos de origen, juegos y tradiciones en su sentido amplio, 2) la noción de territorio, 3) el habla, 4) la identidad confesional.

\section{Conclusión}

La Autonomía y la Interculturalidad son dos componentes de una misma unidad, que reconocen como base la existencia de territorios habitados por diversas culturas que hablan lenguas propias y proceden de una amplia variedad de pueblos y culturas.

La interculturalidad en Nicaragua es incluyente en cuanto a las relaciones de diálogo horizontal entre todos los pueblos que coexisten. El marco jurídico, el sistema educativo, el sistema de salud tradicional ancestral y la sociedad trabajan constantemente en la búsqueda del bien común, en donde se promueve la tolerancia, aceptación multidireccional, respeto, equidad, justicia e igualdad en todos los ámbitos del desarrollo social, económico, político y cultural a fin de construir ciudadanías interculturales.

Es por ello que podemos afirmar que, la Autonomía y la Interculturalidad forman parte de ese proceso permanente de construcción, establecimiento y fortalecimiento de espacios de diálogo, comunicación e interacción entre personas, co- 
munidades y pueblos de diferentes culturas.

\section{Bibliografía}

Alvarado, M. (Dirección). (2008). Magia salvaje y automatismo técnico. La construcción visual de una alteridad americana [Película]. Obtenido de http://www.rchav.cl/2008_12_vid01_ alvarado.html

Alvarez Arzate, M. \&. (2009). Recopilación del conocimiento oral de la lengua y cultura garífunas. Revista Pueblos y fronteras digital, $85-126$.

Alvarez Arzate, M. D. (1992). Aportes al estudio de las políticas urbanas 1979-1989. Managua: UNAN Managua.

Alvarez Arzate, M. D. (2004). Reflexiones sobre los conceptos de etnicidad e identidad urbana. Managua: UNAN Managua. Recuperado el 16 de febrero de 2016, de http://antropologia-nica.blogspot.com/2007/04/reflexiones-sobre-los-conceptos-de.html

Alvarez, M. D., \& Gámez, B. (2011). Inventario sistematizado de los estudios culturales existentes sobre los pueblos de la Costa Caribe de Nicaragua. Sanjosé, Costa Rica: UNESCO.

Angosto Fernández, L. F. (2015). Epistemología, poder y cultura en las antropologías del Sur. Revista de Antropología Iberoamericana. Vol. 10, Núm. 1, 9-26.

Antonio, M. (20 de febrero de 2016). Memoria, olvido y silencio. (M. D. Alvarez Arzte, Entrevistador)

Antonio, M., Alvarez, M. D., Kauffman, M., \& Zamora, D. (2012). Cuaderno Intercultural No. 11. Arte Culinario Tradicional. Identidad y Patrimonio de las Culturas de la Costa Caribe de Nicaragua. San José, Costa Rica: UNESCO.

Appel, M. (2005). La entrevista autobiográfica narrativa: Fundamentos teóricos y la praxis del análisis mostrada a partir del estudio de caso sobre el cambio cultural de los Otomíes en México. Forum: Quialitative Social Research Socialforschung. Volumen 6, No. 2, Art. 16, 1-35.

Augé, M. (1996). Los No Lugares: espacios del anonimato. Barcelona: Gedisa.

Benjamin, W. (. (1936). Der Erzähler. Betrachtungen zum Werk Nikolai Lesskows. In: Orient und Occident. Oriente y Occidente.

Benjamin, W. (. (1972). Abhandlungen Walter Benjamin. Unter Mitwirkung von Theodor W. Adorno und Gershom Scholem. Volumen I / 1: Memorias. Frankfurt: Suhrkamp.

Benjamin, W. (1998). Una imagen de Proust. Madrid: Taurus.

Berger, P. L. (1986). Die gesellschaftliche Konstruktion der Wirklichkeit: eine Theorie der Wissenssoziologie. Frankfurt/M.: Fischer.

Blumer, H. (1969). Symbolic Interactionism. per- 
spective and Method. Berkeley: University of California Press.

Bonfil Batalla, G. (1984). Lo propio y lo ajeno. En A. Colombres, Lo propio y lo ajeno. Publicado en La cultura popular (págs. 79-86). Puebla, México: Premia Editores.

Borja, J. (2000). El espacio público, ciudad y ciudadanía. Barcelona: Electa.

Borja, J. (2000). Laberintos urbanos en América Latina. En D. J. (compilador), Laberintos urbanos en América Latina (págs. 9-34). Quito, Ecuador: Ediciones ABYA YALA.

Bracker, M. (2002). Metodología de la Investigación Social Cualitativa. Managua y Kassel: UPOLI y Universidad de Kassel.

Carrión Mena, F. (2000). Lugares o flujos centrales: los centros históricos. Santiago de Chile: CEPAL.

Carrión, F. (1990). La investigación urbana en América latina: caminos recorridos y por recorrer. Una aproximación desde los países. Quito, Ecuador: Fundación Ford.

Castells, M. (1998). La era de la información. Economía, sociedad y cultura. Vol.2 El poder de la identidad. Madrid: Alianza.

Castells, M. (1998). La Era de la Información: El poder de la identidad. Madrid: Alianza Editorial.

Chomsky, N. (1965). Aspects of the theory of syntax. Cambridge, Massachusetts: MIT Press. da Silva Catela, Ludmila. (2002). El mundo de los archivos. En L. C. Jelin, Los archivos de la represión: documentos, memoria y verdad. Madrid: Siglo XXI de España.

de la Gaza, M. T. (2002). Política de la memoria. Una mirada sobre occidente desde el margen. Barcelona: Anthropos / Universidad Iberoamericana.

Delgado Aburto, L. (2013 ). Memoria y Sandinismo: (en las) articulaciones transnacionales de lo Latinoamericano. Simposio Virtual A Contracorriente, 16.

Díaz, María José y col. (2013, Vol. 22, 2). Políticas de Memoria Desde los Discursos Cotidianos: La Despolitización del Pasado Reciente en el Chile Actual. PSYKHE, 161-173.

Dijk, T. A. (2003). La multidisciplinaridad del análisis crítico del discurso: un alegato en favor de la diversidad. En R. W. Meyer, Métodos de análisis crítico del discurso. (págs. 143-177). Barcelona: Gedisa.

Elias, N. (1990). Compromiso y distanciamiento. Ensayos de sociología del conocimiento. Barcelona: Ediciones Península.

Elizabeth Jelin (comp.). (2010). En E. J. (Comp), Fotografía e identidad. Captura por la cámara, devolución por la memoría. Buenos Aires: Editorial Nueva Trilce.

Feldman, R. (2005). Psicología con aplicaciones a los países de habla hispana. México: McGraw Hill. Interamericana. 
Fragoso, J. E. (2009). Trama de una injusticia: femicidio sexual sistémico en Ciudad Juárez. Hermosillo, Sonora: El Colegio de la Frontera Norte.

Gadamer, H. G. (1960/1972/1975). Wahrheit und Methode, Grundzüge einer philosophischen. Tübingen: J. C. B. Mohr (Paul Siebeck).

García C., N. (1989). Culturas Híbridas. Estrategias para entrar y salir de la modernidad. México: Grijalbo.

García Canclini, N. (1989). Culturas Híbridas. Estrategias para entrar y salir de la modernidad. México: Grijalbo.

García Canclini, N. (1995). Consumidores y ciudadanos: conflictos multiculturales de la globalización. México: Siglo XXI.

92 García, S. (2013). El buen vivir para la población miskitu: aproximación conceptual y propuesta de indicadores para su medición. Managua: HDCA. Human Development and Capability Association.

Geertz, C. (1988). Interpretación de las culturas. Barcelona: Gedisa.

Geertz, C. (1988). La interpretación de las culturas. Barcelona: Gedisa.

Giordano, M. (2012). Fotografía, testimonio oral y memoria. (Re)presentaciones de indígenas e inmigrantes del Chaco (Argentina). Memoria Americana 20 (2), julio-diciembre, 295-321.
Glaser, B. G. (1967). The discovery of grounded theory. Strategies for qualitative research. New York: Gruyter.

Goetz, J.P. \& LeCompte, M.D. (1988). etnografía y diseño cualitativo en ivestigación educativa. Madrid: Ediciones Morata.

Habermas, J. (1993). The Structural Transformation of the Public Sphere. An Inquiry into Category of a Bourgeois Society. Cambridge, Massachusetts: MIT Press.

Halbwachs, M. (. (1949/2004). Memoria Colectiva. Zaragoza: Prensas Universitarias de Zaragoza.

Halbwachs, M. (. (1995). Memoria colectiva y memoria histórica. Traducción de un fragmento del capítulo II de La mémoire collective, París, PUF, 1968. Por Amparo Lásen Díaz. Revista Española de Investigaciones Sociológicas (REIS), 209-219.

Hall, S. (2010). Sinb garantías. Trayectorias y problemáticas en estudios culturales. Quito: Envión Editores.

Heidegger, M. (1927/1986). Sein und Zeit, 1. Edición 1927, 16. Edición 1986. Tübingen: Niemeyer.

Himnkelhamert, F. (1989). La crisis del socialismo y el tercer mundo. Revista Pasos, 1-6.

INIDE. (2005). VIII Censo de Población y IV de Vivienda. Managua: INIDE. 
Jelin, E. (. (2001). ¿De qué hablamos cuando hablamos de memorias? En E. Jelin, Los trabajos de la Memoria (págs. 17-37). España: Siglo Veintiuno Editores.

Jelin, E. (. (2002). Los trabajos de la memoria. Memorias de la represión en América. Madrid y Buenos Aires: Siglo XXI de España y Siglo XXI de Argentina.

Jelin, E. (. (2012). La fotografía en la investigación social: algunas reflexiones personales. Memoria y Sociedad, Vol.16, No.33. Bogotá, julio-diciembre 2012, 55-67.

Kallmeyer, W. \&. (1976). Konversationsanalyse. Studium Linguistik 1, 1-28.

Kinloch, F. (1997). Conflicto étnico, geopolítica e identidad. Estudios Fronterizos, Núm. 40, julio-diciembre, 95-114.

Kondratiev, N. D. (1926/1956). Los grandes ciclos de la actividad económica. En G. H. (Ed.), Ensayos sobre el Ciclo Económico: 3556 (págs. 35-56). México: Fondo de Cultura Económica.

Kotliarernco, María Angélica y col. (1997). El estado del arte en resiliencia. Washington, D.C.: OPS.

Krotz, E. (1993). La producción de la antropología en el sur: características, perspectivas, interrogantes. Alteridades, Año 3, Núm. 6, 5-11.
Lásen Díaz, A. (1995). Nota de introducción al texto de Maurice Halbwachs. REIS, 203-208.

Law, H. (20 de febrero de 2016). Memoria, silencio y olvido. (M. D. Alvarez Arzate, Entrevistador)

Lincoln, Y.S. \& Guba, E.G. (1985). Naturalistic Inquiry. Beverly Hills, London,. New Delhi: Sage Publications.

López, A. (16 de diciembre de 2007). Recopilación del conocimiento oral de la lengua y cultura garífunas. (M. D. Alvarez, Entrevistador)

Mackenbach, W. (. (2004). Cicatrices : un retrato del cuento centroamericano. Managua: Ediciones Centroamericanas Anama.

María José Reyes y col. (2013). Políticas de Memoria Desde los Discursos Cotidianos: La Despolitización del Pasado Reciente en el Chile Actual. Psykhe, Vvol.22 No.2 Santiago, noviembre, 161-173.

Mary Douglas \& Baron Isherwood. (1979). El mundo de los bienes. Hacia una antropología del consumo. México: Grijalbo.

Mayring, P. (2007). Generalisierung in qualitativer Forschung. Forum: Qualitaive Social Research. Volume 8, No. 3, Art. 26 - September 2007, 1-8.

McLean, M. (20 de febrero de 2016). Memoria, olvido y silencio. (M. D. Alvarez Arzate, Entrevistador) 
Mendoza, J. (2005). Exordio a la memoria colectiva y el olvido social. Athenea Digital - Num. 8 , otoño 2005, 1-26.

Mendoza, M. (23 de abril de 2013). Sistematización de Prácticas Exitosas. (MDA, Entrevistador)

Middleton, David y Edwards, Derek. (comps.). (1992). Memoria Compartida. La Naturaleza Social del Recuerdo y del Olvido. Barcelona: Paidós.

Mignolo, W. (. (1996). Herencias coloniales y teorías postcoloniales. En B. G. Stephan, Cultura y Tercer Mundio: 1 Cambios en el Saber Académico, Cap. IV. (págs. 99-136). Caracas, Venezuela: Nueva Sociedad.

Mignolo, W. (. (2000). La colonialidad a lo largo

y a lo ancho: el hemisferio occidental en el horizonte colonial de la modernidad. En E. L. (Editor), La colonialidad a lo largo y a lo ancho: el hemisferio occidental en el hjorizonte colonial de la modernidad (págs. 55-85). Buenos Aires: CLACSO.

Mignolo, W. (. (2003). Historias locales / diseño globales. Colonialidad, conocimientos subalternos y pensamiento frionterizo. Sevilla: Ediciones Akal.

Mignolo, W. (. (2008). La opción de-colonial: desprendimiento y apertura. Un manifiesto y un caso. Tabula Rasa No. 8, 243-281.
Monsiváis, C. (2004). Monsiváis, Carlos. Represión santificada. Proceso, 1483, 23, págs. 1416.

Moreno, E. (. (28 de febrero de 2016). Memoria, olvido y silencio. (M. D. Alvarez Arzate, Entrevistador)

Moreno, E. (28 de febrero de 2016). Memoria, olvido, silencio. (M. D. Alvarez Arzate, Entrevistador)

Nora, P. (2008). Entre mémoire et histoire, la problématique des lieux de mémoire (1939). Traducido del francés por Laura Masello. Montevideo: Trilce.

Ochoa, L. M. (2012). Museo, memoria y Derechos Humanos. Bilbao: Universidad de Deusto.

Oevermann, U. e. (1983). Die Methodologie einer "Objetiven Hermeneutik". Zedler: P. / Moser, H. (Eds.).

Peller, M. (2010). Un recuerdo de infancia. Juego, esperiencia y memoria en los escritos de Walter Benjamin. Nómadas. Revista Crítica de Ciencias Sociales y Jurídicas, No. 27, 1-11.

Pliego, C. R. (2011). De memoria y memorias. Un acercamiento a "Funes el memorioso" a partir de Walter Benjamin. Casa del tiempo, Vol. III época IV número 38-39, diciembre 2010 - enero 2011, 25-30.

PNUD, I. N. (2005). Informe de Desarrollo Humano 2005 "las Regiones Autónomas de la Costa Caribe”. Managua: PNUD. 
Pollak, M. (2006). Memoria, olvido, silencio. La producción social de identidades frente a situaciones límite. La Plata: Ediciones Al Margen.

Radley, A. (1992). Artefactos, memoria y sentido del pasado. En D. (. Middleton, Memoria Compartida (pág. 256). Barcelona: Paidós.

Ramírez, P., \& Aguilar, M. (2006). Pensar y habitar la ciudad. Afectividad, memoria y significado en el espacio urbano contemporáneo. Barcelona: Antrophos Editorial.

Reguillo, R. (2000). Identidades culturales y espacio público. Un mapa de los silencios. Diálogos de la comunicación No. 59-60, 75-86.

Reyes Andriani, M. J. (2015). Construcción de políticas de memoria desde la vida cotidiana. Psicologia \& Sociedade, 27(2), 341-350.

Ribeiro, D. (1970/1992). Las Americas y la civilizacion: Proceso de formacion y causas del desarrollo desigual de los pueblos americanos . Caracas: Fundacion Biblioteca Ayacucho.

Ricardo Pinilla \& Ana María Rabe. (2010). Los espacios de la memoria en la obra de Walter Benjamin. Constelaciones. Revista de Teoría Crítica. No. 2, 289-300.

Ricoeur, P. (. (2002). Definición de la memoria desde un punto de vista filosófico. En E. F.D. (dir.), ¿Por Qué Recordar? (págs. 24-28). Barcelona: Granica.

Ricoeur, P. (2000/2004). La memoria, la historia, el olvido. Buenos Aires: Fondo de Cultura Ecnómica de Argentina.
Rivas, G. L. (1995). Nación y pueblos indios en el neoliberalismo. México: Plaza y Valdés.

Rodrigo, A. M. (1999). Las estrategias identitarias: entre el Ser y el Hacer. Afers Internacionals, núm. 43-44, diciembre 1998- enero 1999, 11 15.

Rodrigo, M. A. (2004). Cuestionamientos, características y miradas de la interculturalidad. Sphera Pública, núm. 4, 53-68.

Rodríguez, I. (2001). Convergencia de tiempos. Estudios subalternos/contextos latinoamericanos Estado, cultura, subalternidad. Amsterdam/Atlanta, GA: Rodop.

Rutter, M. (1993). Resilience: Some conceptual considerations. Journal of Adolescent Health, vol. 14, n.8, 626-631.

Saussure, F. (1945). Curso de Lingüística General. Vigésimocuarta edición. Buenos Aires: Losada.

Schütz, A. (1971). Das Problem der Sozialen Wirklichkeit. Den Haag: Nijhoff.

Schütze, F. (1983). Biographieforschung und narratives Interview. Neue Praxis, 283-293.

Schütze, F. (1987). Die Rolle der Sprache in der soziologischen Forschung. En U. A. (Eds.), Soziolinguistik. Ein internationales Handbuch zur Wissenschaft der Sprache und Gesellschaft (págs. 520-553). Berlin: de Gruyter. 
Schütze, F. (1987). Symbolischer Interaktionismus. En N. D. Ulrich Ammon, Soziolinguistik. Ein internationales Handbuch zur Wissenschaft der Sprache und Gesellschaft (págs. 520-553). Berlin: de Gruyter.

Singer, D. (2008). Construcción social de la memoria: el anhelko de esclarecimiento a la luz de tres noveles centroamericanas. Inter-c-a-mbio. Año No.5, n, 6., 43-61.

Sociedades Bíblicas, U. (1974). Dawan Bila- La Raya Waungkataya. Naiwa Yua Uplika Nani Dukiara. Traducción a partir de la versión española "Dios Habla Hoy". Sociedades Bíblicas Unidas.

Stanek, M. (1994). Big Man And Big Woman in the village-elite in the town. Basel: Basel : Eso Conference.

96 StClair, A. (21 de febrero de 2016). Memoria, olvido y silencio. (M. D. Alvarez Arzate, Entrevistador)

Todorov, T. (junio de 2015). La memoria tiene una potencia que la historia nunca alcanza. Letras Libres. En: http://www.letraslibres. com, 1-11.

UNESCO. (2002). Declaración Universal sobre la Diversidad Cultural. Johannesburgo: UNESCO.

van Dijk, T. (1999). Análisis Crítico del Discurso. Anthropos 186, 23-36.
Vásquez, F. (2001). La memoria como acción social. Relaciones, significado e imaginario. Barcelona: Paidós.

Wallerstein, I. (. (2005). Análisis de Sistemas Mundo. Una Introducción. México: Siglo XXI Editores.

Wallerstein, I. (. (2006). Abrir las Ciencias Sociales. Informe de la Comisión Gulbenkian para la reestructuración de las ciencias sociales. México: Siglo XXI - UNAM.

Wallerstein, I. (. (2006). Análisis de sistemas-mundo. Una introducción. Madrid: Siglo XXI Editores.

Watzlawick, P. (1984). El arte de amargarse la vida. Barcelona: Editorial Herder. S.A.

Weber, M. (1964). Economía y sociedad. Esbozo de sociología comprensiva ("Wirtschaft und Gesellschaft”). trad. J. Medina Echavarría, ed. J. Winckelmann. México, 1964: FCE.

Witzel, A. (2000). Das problemzentrierte Interview. FQS FRorum Quilitative Social Research. Volume 1, No. 1, Art. 22.

Yakovlev, A. (1991). Lo que queremos hacer con la Unión Soviética. Barcelona: Alianza Editorial. 